\title{
The new coronavirus disease (COVID-19): What do we know so far?
} By

Sammer Tang, Public Health Registrar- Gloucestershire Hospitals NHS Foundation Trust; Public Health Lead- College of Paramedics

Mike Brady, Clinical Desk Manager - Welsh Ambulance Service NHS Trust

Jo Mildenhall, Clinical Lead for Mental Health- South Western Ambulance Service NHS Foundation Trust

Ursula Rolfe, Deputy Head of Department of Midwifery and Health Sciences - Bournemouth University

Alexandra Bowles, Senior Lecturer in Applied Pharmacology - University of the West of England Kirsty Morgan, Senior Quality Manager - East Midland Ambulance Services NHS Trust

Email for correspondence: Sammer.Tang@nhs.net

\section{Abstract:}

Severe acute respiratory syndrome coronavirus 2 (SARS-CoV-2) is a novel coronavirus that causes the new Coronavirus disease (COVID-19). The symptoms range from mild to severe with a higher incidence of severe cases seen in patients with risk factors such as older age and comorbidities. COVID-19 is mainly spread through the inhalation of respiratory droplets from coughing or sneezing or via contact with droplet-contaminated surfaces. Paramedics should be aware that some aerosol generating procedures (AGPs) may put them at a higher risk of contracting the virus via possible airborne transmission. The use of remote triage clinical assessment is likely to increase as a result of the pandemic. There is no curative drug treatment for the virus and some medications may exacerbate its effects or make patients more susceptible to it. Paramedics should accept that feeling stressed by the pandemic is a natural response. Official guidelines and advice are evolving continually as the evidence on SARS-CoV-2 and COVID-19 grows. Paramedics should keep up to date with the latest clinical guidance from their employers.

Keywords: Coronavirus; COVID-19; SARS-CoV-2; Pandemic; Paramedic; Infection prevention and control; Aerosols; Aerosol Generating Procedures; Novel virus; Wellbeing 


\section{COIVID-19: What do we know so far?}

\section{Introduction}

In late December 2019, a novel coronavirus was identified in Chinese City of Wuhan, causing severe respiratory disease including pneumonia [1]. In January 2020, the World Health Organisation (WHO) named this novel coronavirus as Severe Acute Respiratory Syndrome Coronavirus 2 (SARS-CoV-2) and the associated disease as COVID-19 [1-3]. The first confirmed case of COVID-19 in the UK was recorded on the $31^{\text {st }}$ January 2020 [4] and the number of cases continues to rise since then (Figure 1).

Similar to other coronaviruses that have infected humans, SARS-CoV-2 are enveloped, positivesense, single stranded RNA viruses that cause respiratory infections [5, 6]. As per most human coronavirus infection, most SARS-CoV-2 infections induce mild respiratory disease and symptoms [7, 8].

\section{Epidemiology}

As of $7^{\text {th }}$ April 2020, there are over 1,270,000 cases of COVID-19 diagnosed worldwide with over 68,000 confirmed fatality [9]. In UK, there are a cumulative total of over 60,000 confirmed cases and resulted in 7,097 COVID-19 related deaths [10].

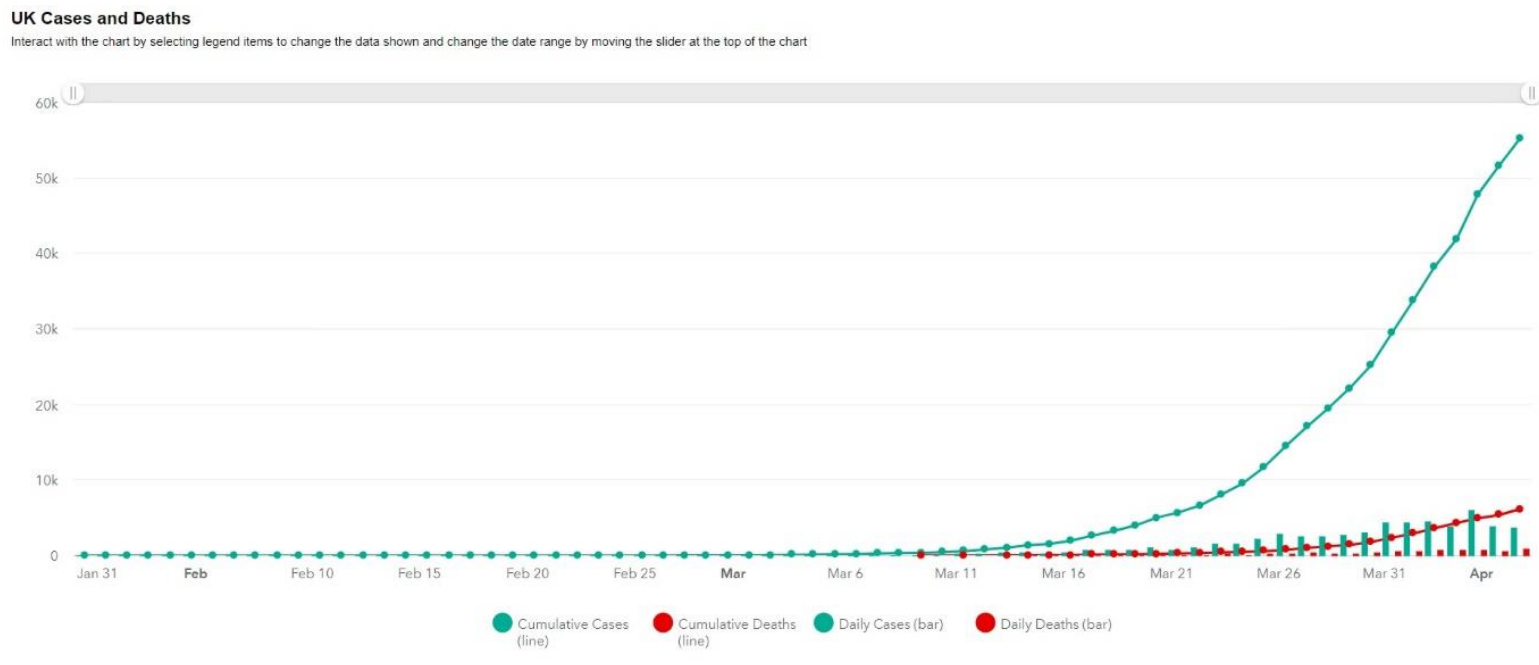

It is estimated that around $5-10 \%$ admitted patients would become critically unwell and may require respiratory support in intensive care/ therapy units $[11,12]$.

Furthermore, the estimated basic reproduction number $\left(R_{0}\right)$ was around 2-2.5 $[13,14]$ in early April 2020 which means a COVID-19 case could infect an average 2-2.5 people in a population where everyone is susceptible who does not have specific immunity against it [15].

COVID-19 has an estimated median incubation period of 4-6 days. Of those who develop symptoms, $97.5 \%$ will do so within 11.5 days $[2,5,11,13,14,16]$. Most patients will not be infectious until the onset of symptoms and their infectiousness depends on the severity of their symptoms and stage of their illness. However, due to the inter-individual variations in the length of incubation period, some infected individuals could be infectious before symptoms are developed and there are reported cases of asymptomatic transmission. $[5,17]$. 


\section{Infection prevention and control (including Personal Protective Equipment)}

Standard infection control precautions (SIPCs) and transmission based precautions (TBPs) must be used when managing patients with suspected or confirmed COVID-19. SICPs are the universal precautions that should be applied by paramedics routinely to minimise the risks relating to the transmission of infections from all human body fluids secretions and excretions. In contrast, TBPs are additional infection control precautions as SIPCs alone are inefficient in preventing the cross transmission of COVID-19 [18].

From the information that is available regarding SARS-COV-2 viruses, it is believe that they have similar route of transmission to SARS-CoV-1 and MERS-CoV, this is through respiratory droplets $(>5 \mu \mathrm{m})$ which are produced when an infected person coughs or sneezes. These droplets can be inhaled into the lungs by people nearby or could land on surfaces where the viruses could survive for a period of time and could then infect others in contact with the contaminated surfaces [18]. However, SARS-CoV-2 can be isolated in the gastrointestinal tract, saliva, and urine, these routes of potential transmission could not be ruled out at this time $[11,19]$.

In addition, some medical and patient care procedures (known as aerosol generating proceduresAGPs) could generate airborne particles contaminated by known infectious substances (aerosols) which are less than 5 micrometres $(\mu \mathrm{m})$ in size[20]. These aerosols can remain suspended in the air, travel over a distance and may cause infection if they are inhaled. AGPs could be linked to a significantly increased risk of healthcare workers contracting SARS-Cov-1 during the previous SARS outbreak in 2003 [21]. Furthermore, there is recent evidence to demonstrate that SARS-CoV-2 has similar properties to the SARS-CoV-1 which remains viable in aerosol form $(\leq 5 \mu \mathrm{m})$ [22]. This would suggest COVID-19 could be airborne during AGPs.

A systematic review by Tran and colleagues[23] had summarised the risks of SARS transmissions in healthcare workers when carrying out different aerosol generating procedures. This informed the New and Emerging Respiratory Virus Threats Advisory Group's (NERVTAG) decision on which procedures are included on the list of AGPs for the UK. Some of the common AGPs conducted in the pre-hospital care settings include some procedures related to cardiopulmonary resuscitation e.g. Advanced airway procedures-laryngoscopy, intubation, extubation, surgical airway; Manual ventilation; Suctioning; Management of Choking, Foreign body airway obstruction removal[24].

It is worth noting that even though nebulisation itself is an aerosol generating procedures, the evidence suggested the aerosol does not contain any viruses and minimal viable bacteria were recovered[25]. During nebulisation, the aerosol derives from a non-patient source (the fluid in the nebuliser chamber) and does not carry patient-derived viral particles. If a particle in the aerosol coalesces with a contaminated mucous membrane, it will cease to be airborne and therefore will not be part of an aerosol. Staff should use appropriate hand hygiene when helping patients to remove nebulisers and oxygen masks.

A Canadian study recommended the use of metered dose inhaler of bronchodilators if available to minimise the theoretical risk of viral aerosolization from nebulisation[26].

With an increased level of COVID-19 in the community and the UK is entering the sustained transmission phase of the pandemic in early April 2020, Public Health England recommended two levels of personal protective equipment for the Ambulance sector[24] (Figure 2 \& Figure 3)Figure 2: Level 2 and 3 PPE with respiratory hood:

\section{Level 2: All ambulance attendances regardless of patient symptoms}


- Disposable gloves

- Disposable apron

- Fluid repellent surgical mask

- Eye protection

Level 3: Aerosol generating procedures to be carried out

- Disposable gloves

- Fluid repellent coveralls

- FFP3 or powered respirator hood

- Eye protection

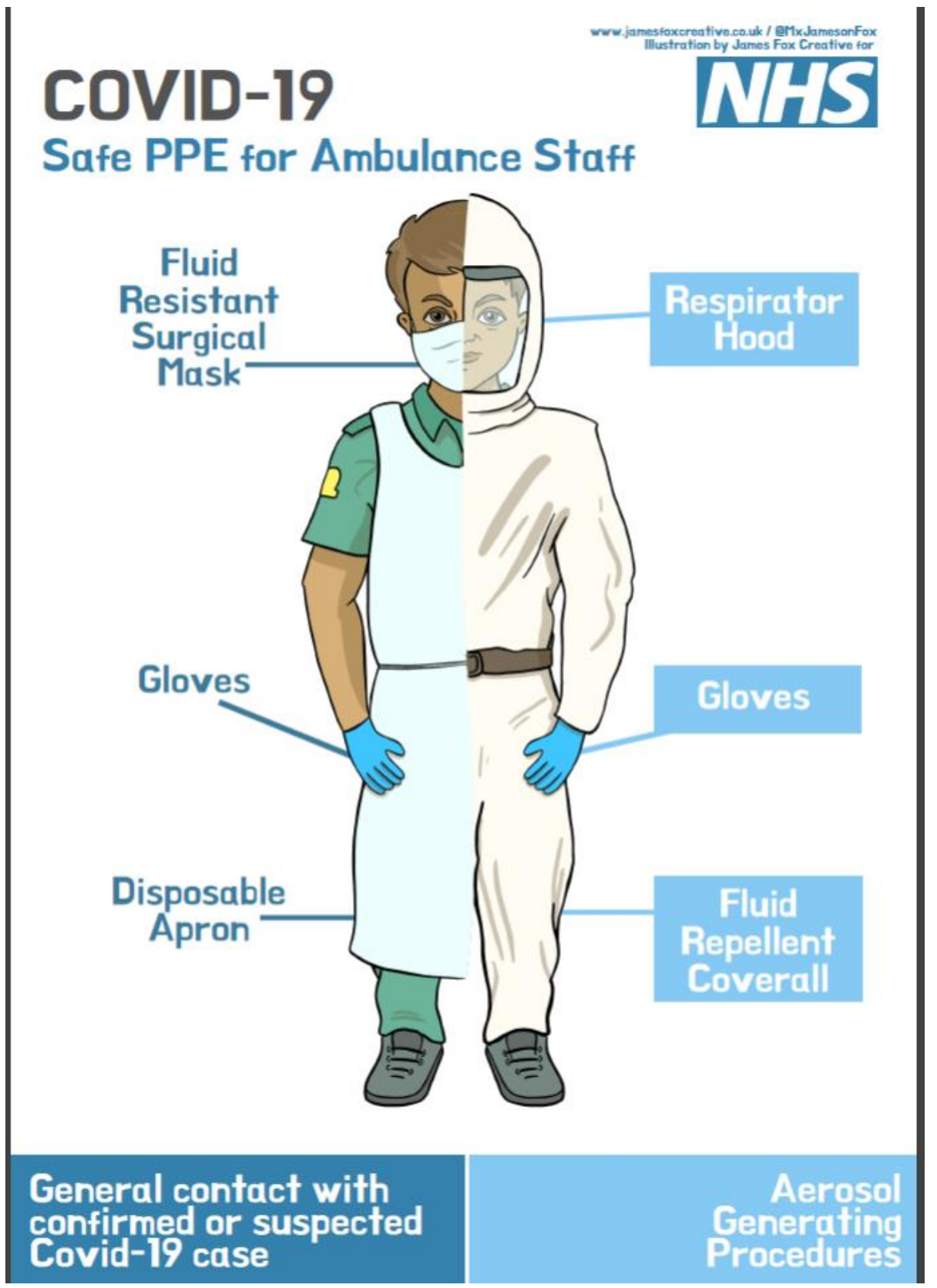

Figure 2: Level 2 and 3 PPE with respiratory hood

Credit: James Fox 


\section{COVID-19

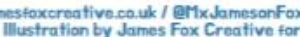 WhS}

Safe PPE for Ambulance Staff

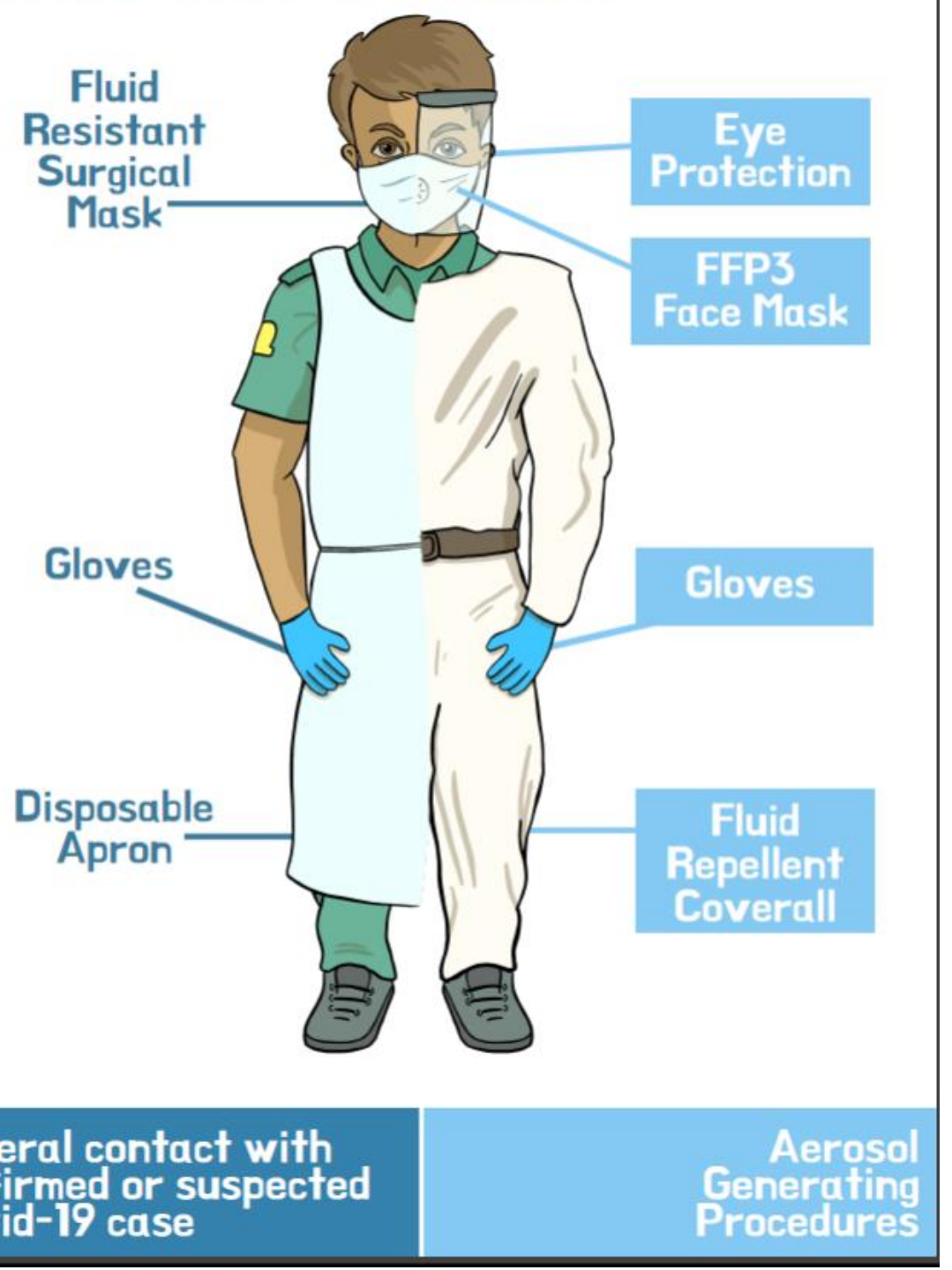

Figure 3: Level 2 and 3 PPE with facemasks

Credit: James Fox

Clinical Assessment of suspected/ confirmed COVID-19 patients

Fever $\left(>37.8^{\circ} \mathrm{C}\right)$, cough and myalgia or fatigue are the three most common symptoms presented in patients who are infected with SARS-Cov-2 $[2,5,7,8,11]$. Other less common symptoms include sputum production, sore throat, headache, haemoptysis and diarrhoea $[7,8]$.

The current possible case definition of COVID-19 (as of 13 March 2020) in the UK [27] is as follows:

Patients required hospital admission (as decided by a hospital practitioner with an expectation that the patient will need to stay at least one night) and have either:

- Clinical or radiological evidence of pneumonia

- Acute respiratory distress syndrome 
- Influenza like illness (fever $\geq 37.8^{\circ} \mathrm{C}$ and at least one of the following respiratory symptoms, which must be of acute onset: persistent cough (with or without sputum), hoarseness, nasal discharge or congestion, shortness of breath, sore throat, wheezing, sneezing).

In addition, paramedics are advised that COVID-19 infection should be considered in all cases of respiratory infection in the pre-hospital emergency care settings [24]. If patients meet the below criteria they are to be classified as a possible or confirmed case.

- Acute respiratory distress syndrome

Or

- High temperature (of $37.8^{\circ} \mathrm{C}$ or higher)

- And at least one of the following which must be of acute onset:

- Persistent cough (with or without sputum), hoarseness, nasal discharge or congestion, shortness of breath, sore throat, wheezing or sneezing

Older people (>60 years), men, patients with underlying chronic diseases (such as respiratory diseases, hypertension, diabetes) or comorbidities resulting in weaker immune functions are all linked to increased risks of developing severe illness from COVID-19 [5, 8, 11].

Paramedics should use existing thresholds for vital signs and early warning score (such as NEWS2 score/ POP score etc.) to guide their management of suspected/ confirmed COVID-19 patients, as abnormal vital signs such as increased respiratory rate, increased pulse rate and low oxygen saturation (<93\%) on air were linked to increase morbidity and mortality in reported cases [2].

In addition, Paramedics should be mindful that both adult and child death are increasing from a non COVID-19 related diseases. This could be related to people's fear and often delay presenting to healthcare because they perceive a higher risk of contracting COVID-19 if they attend healthcare facilities.

Patients who are well enough to remain in the community with new continuous cough and/or fever $\left(>37.8^{\circ} \mathrm{C}\right)$ should be advised to stay at home for self-isolation and their family should be advised to be self-isolating for 14 days as per current government advice [28]. Additional advice for those who are in self-isolation including:

- Stay in a well-ventilated room, use a separate bathroom if available; if they have to share the bathroom clean it regularly, use separate towels, wear a clean mask when using a communal kitchen, use separate crockery and cutlery

- Wash hands with soap and water before cooking and eating and after using the toilet

- Have food, medication, and supplies delivered to you

- Double bag and seal all waste. These bags should be tied securely and kept separate from other waste. This should be put aside for at least 72 hours before being put in your usual external household waste bin.

- Seek prompt medical attention if their illness or the illness in any household members is worsening. If it's not an emergency, contact NHS 111 online. If they have no internet access, they should call NHS 111. If it is an emergency (such as reduced level of consciousness, acute shortness of breath, cyanosis etc.) and they need to call an ambulance, dial 999 and inform the call handler or operator that they or their relative have coronavirus symptoms. 
Remote telephone clinical assessment of suspected/ confirmed COVID-19 patients

At a time where much of the world is having to adapt to working remotely and is having to embrace the use of technology more in their personal lives; so are paramedics in their professional lives. Telephone triage, also known as remote clinical decision making (RCDM), has long been a wellrecognised and an increasingly used method of managing a growing demand on the ambulance and primary care services [29]. Such services, along with advice and referral-based service (NHS 111, NHS 24 , and NHS Direct) have seen a rapid and significant increase in call volume in response to COVID$19[30]$.

Guidance released from NHS England and NHS Improvement [31] suggests that in response to COVID-19 healthcare providers should roll out remote consultations using video, telephone, email and text message services for all important routine activity as soon as possible. In addition to this, they also ask that clinical staff themselves, where possible, work from home and consider how they can use telephone-based or digital / video-based consultations and advice for patients.

RCDM is fast becoming a recognised speciality in clinical practice and multiple professional career frameworks. This practice is normally underpinned by significant post registration experience, bespoke training and more recently specific RCDM higher education [29]. The impact of the significant increase in COVID-19 call volume when coupled with guidelines such those mentioned earlier has meant that RCDM has become something upon which a range of clinicians have had little choice but to rely on entirely to carry out an increasing amount of their practice; with a lack of experience, training, and specialist education, and in home office environments away from traditional support mechanisms.

Those staff currently working in telephone triage will be well adept to practising remotely, and various clinical decision support software tools currently being used have activated their pandemic flu algorithms to support such clinicians more in their assessment; in addition to changing demand management processes. Experienced RCDM staff are maintaining capacity and following public health guidance by utilising home working packages with the use of digital phone systems and remote computer-aided dispatch modules. Additional video-based platforms have been rapidly rolled out to augment this method of remote practice further and reduce some risk. Increased surge capacity can also be realised from these homeworking triage staff through the use of ad hoc overtime in response to spikes in call demand and by freeing up space in clinical hub estates for newer staff who require more intensive support and guidance.

Many clinicians, however, favour not to practice over the phone and for some it will not be possible at all. While there is evidence that suggests telephone triage is generally safe in a normal cohort of general medical patients [32], the risks associated with non-face-to-face clinical practice are also well known and explored [33]. Telephone triage clinicians can assess and manage an estimated 3-4 patients per hour. In contrast, ambulance-based clinicians may only see one patient during this time. Many services are looking to redeploy clinical staff, recruit new temporary staff, utilise military medical support, and more readily use agency staff to provide this remote assessment of patients to help with managing an overwhelming COVID-19 based demand.

To support clinicians new to working in this specialised area of clinical practice, the Royal College of General Practitioners [34] have released guidance on conducting telephone consultations; which while helpful, provides little more than generic assessment and communication types adapted somewhat for remote practice. Greenhalgh et al. [35] however, provide a more robust case study approach to the remote management of covid19 patients in an article entitled 'COVID-19: a remote assessment in primary care'. This article presents the guiding principles to remote assessment by 
phone or video and provides a call structure consistent with other widely recognised tools. Those clinicians finding themselves new to remote practice should review this piece and others relevant articles.

While telephone triage was once an additional method of managing demand, it has, in response to COVID-19, become a method of managing the majority of demand; and will do so more as call volume increases. As a result, it must now be asked if the response to COVID-19 has created a context in which the face to face clinical consultation model has irrevocably been questioned; and telephone / remote triage and assessment becomes the primary method of future clinical practice.

\section{Use of Medicines in COVID-19 patients}

Supportive management is key with no medicines yet approved for the treatment of COVID-19 but a number currently undergoing clinical trials including within the United Kingdom.[36]

It has been suggested that the use of Angiotensin Converting Enzymes Inhibitors (ACEIs) and Angiotensin Receptor Blockers (ARBs) may increase the likelihood or severity of COVID-19 [37]. This hypothesis is based on the theories that ACE-2 facilitates the entry of SARS-CoV-2 and that ACEIs/ARBs have the potential to upregulate ACE2 as observed in animal studies but with no consistent evidence from human data [38].

There is no evidence available to support the routine discontinuation of ACEIs or ARBs. Paramedics should encourage patients to continue their prescribed medications unless specifically advised to stop by their medical team $[39,40]$.

Paramedics with prescribing responsibilities should consider whether the ACEI or ARB are prescribed for current or long-term benefits. If the prescribing of ACEIs/ARBs is for current benefits (such as severe uncontrolled hypertension or heart failure), stopping these medications may lead to a rapid deterioration. For those patients who are taking ACEIs/ ARBs for long-term benefits, precautionary principles should be applied including withholding ACEIs/ARBs during acute infection which could reduce the theoretical short-term risks during acute infection [41]. It may be beneficial to ask the patient to contact the original prescriber or their own general practitioner for further information.

Paramedics are advised to continue with their existing pre-hospital emergency care drug interventions as indicated as there is no current evidence to suggest the appropriate use of intravenous fluids or glyceryl trinitrate (GTN) is linked to worsening conditions in COVID-19 patients.

The media reported that the use of Non-Steroidal Anti-Inflammatory Drugs (NSAIDs) could worsen COVID-19 due to the theoretical risk of ibuprofen increasing the expression of ACE-2 although this has only been shown in animal studies as above $[37,42]$. Known NSAID effects including reduced inflammation or fluid retention may also contribute to the pneumonia seen in severe cases [27]. A recent systematic review found no published evidence for or against the use of NSAIDs in COVID-19 patients [43].

Paramedics should take a cautionary approach by avoiding using NSAIDs as the first-line option for managing the symptoms of COVID-19 as recommended by UK guidance [44]. However, if patients are prescribed NSAIDs for existing conditions, they should continue these as directed by their healthcare professional $[44,45]$. While NSAIDs, ACEIs or ARBs should not be discontinued routinely due to COVID-19 this may be recommended in patients who become acutely unwell due to the risk of acute kidney injury [46]. 


\section{Resuscitations in suspected/ confirmed COVID-19 patients}

Resuscitation Council UK (RCUK) have published resuscitation guidelines for healthcare professional managing patients with COVID-19 or suspected patients with COVID-19 [47]. The current guidelines for advanced life support for COVID-19 patients is in Figure 4.

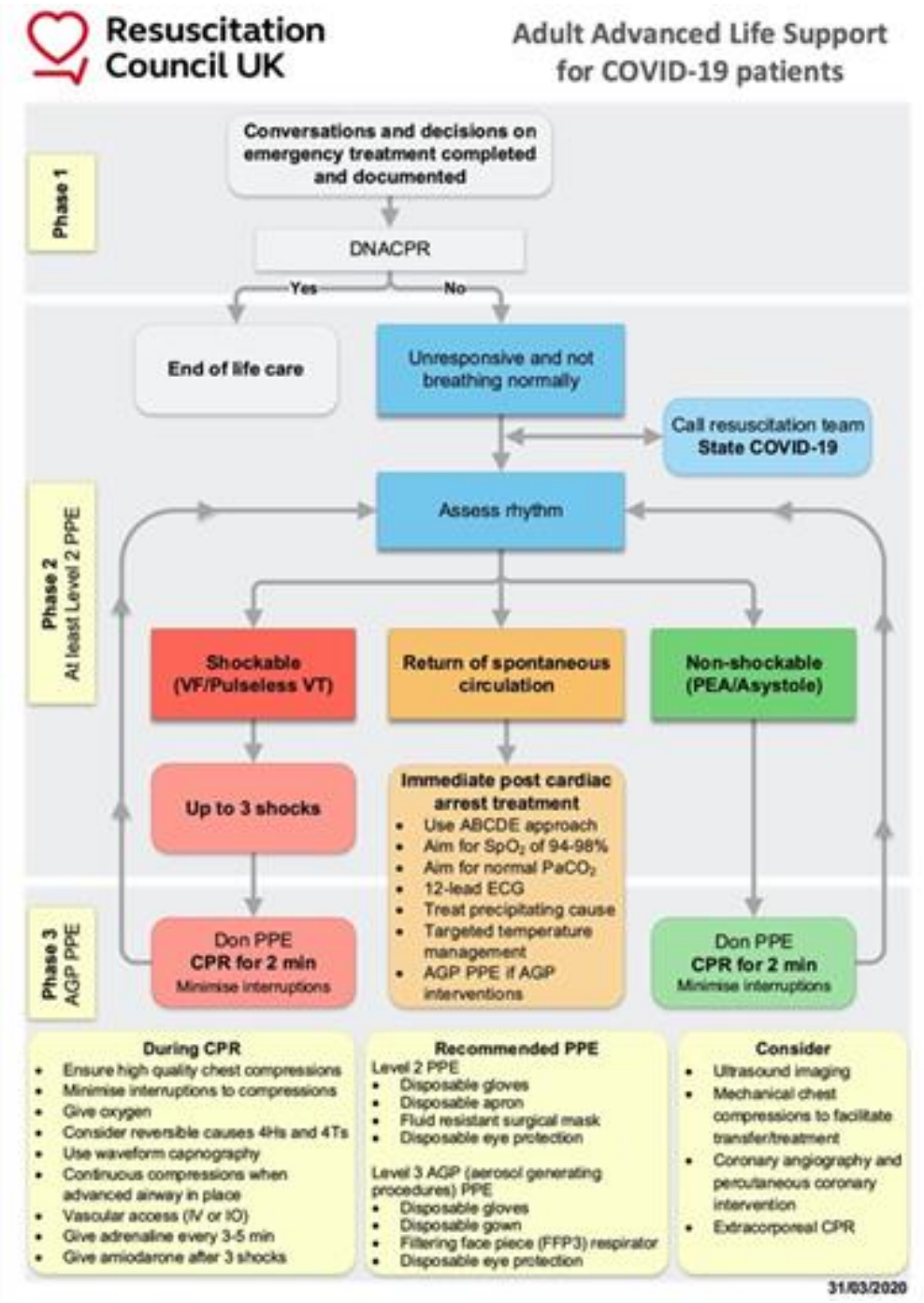

Figure 4: Adult Advanced Life Support for COVID-19 patients Used with kind permission from Resuscitation Council (UK)

The RCUK guidelines are not specific to pre-hospital care but are adapted and applicable within the remit of the healthcare provider [47]. RCUK suggests that applying defibrillator pads during a cardiac arrest procedure can be done without PPE as "it may negate the need for chest compressions" [47]; once the defibrillator has been attached and used if appropriate, the rest of the team, where applicable, can put on the appropriate level 3 PPE as per the advice discussed above. RCUK [47] emphasise the importance of decision-making processes prior to the time of cardiac arrest and whether to commence $\mathrm{CPR}$, however, this is not always possible in the pre-hospital environment.

Once the initial patient assessment has been made and the patient has a shockable rhythm, up to 3 shocks is recommended [48]. This is specifically for the use of manual defibrillators. RCUK recommend giving the first shock as usual, then reassess the rhythm after the first shock [48]. If the patient remains in a shockable rhythm, apply a further shock. If there is a potential perfusing rhythm, check for a pulse. If the patient has now moved to an non-shockable rhythm, start chest compressions with the appropriate PPE [48]. 
RCUK's current guidelines state that rhythm assessment and defibrillation are not aerosolgenerating procedures (AGPs); However, initiating cardio-pulmonary resuscitation (CPR) is considered to be AGP. Also note that the post-resuscitation care recommends an oxygen saturation level of $94-98 \%$ due to acute lung injury and aspiration induced lung injury caused by COVID-19 [48].

One of the biggest concerns lies around AGPs during resuscitation. The current position of RCUK is that chest compressions alone are an AGP and staff should wear level 3 PPE for AGPs; while the current PHE guidance explicitly stated that chest compression and defibrillation are not AGPs. International guidelines currently list CPR as an AGP but they do not universally make clear which steps of the CPR process (e.g., defibrillation, chest compression, airway and ventilation) are AGPs.

With the continued escalation of COVID-19, guidelines and protocols will continue to be updated in response to ever-growing research, experience and clinical trials. During such uncertain times, it remains the clinician's responsibility to deliver the best care within their remit but also to do so within personal safety parameters.

\section{Stress management and wellbeing}

As noted within this article, the pandemic brings with it new clinical challenges and requires ambulance clinicians to work and think differently about their practice. Combined with a potential increase in attendance to seriously unwell, dying and deceased patients as the contagion reaches its peak, paramedics are likely to find themselves having to make critical clinical decisions which are both ethically and morally challenging to their professional practice [49], and which may be opposing to their own personally held values and beliefs. This may result in 'moral injury' [50] whereby individuals experience thoughts relating to themselves and/or others which are negative and critical (such as thinking that they have failed a patient or not provided the care which they know a patient would have received under 'normal' circumstances). This may lead to feelings of intense guilt, shame and/or blame [51]. These thoughts may become injurious due to the longer-term impact upon an individual's mental wellbeing in terms of the development of distress, anxiety, depression, posttraumatic stress and potentially suicidal ideation [52].

The uncertainty and severity of the epidemiological progression of the disease will naturally result in individuals feeling extremely conflicted in their roles as healthcare professionals, and in their 'roles' in personal life such as son, daughter, husband, wife... The psychological impact that this has can be profound. In particular, this will likely include heightened emotional and behavioural responses to potential pathogenic exposure including extreme fear and anxiety at risk of infection of self and others, and intense feelings relating to a perceived elevated risk of mortality.

Along with shift working, exhaustion and fatigue, limited time for rest and to eat nutritious meals, and with the challenges of physical distancing and social isolation which may be impacting upon family life, it potentially makes for an extremely distressing and psychologically traumatic time.

Feeling scared and fearful at the risk of uncertainty is a very difficult thing to sit with; we usually like some kind of order and 'normality' to our lives, and this is currently being challenged. To feel this way however, is a normal human response to a situation which is far from normal [53].

Whilst many people are likely to experience distress at some point, if not throughout the pandemic, some individuals may also experience a hopeful outlook with an increased sense of personal strength which enhances feelings of resilience [54]. As they appraise the impact of this viral disease in terms of their own beliefs and values, it brings with it, existential considerations and thoughts which lead to a changed perception of life with new priorities and more meaningful personal relationships which can bring enhanced psychological wellbeing [55]. 
Importantly, connecting and talking with others is something which is so fundamental, yet can provide much needed offloading of distressing and overwhelming thoughts, normalise feelings, and as research studies have highlighted, is key to the healing process. Feeling supported and cared for, and experiencing kindness and compassion, enhances wellbeing, promotes recovery and protects mental health [56].

As we move through the pandemic to the peak of contagion and in the days and months afterwards, it is human connectivity and the support of each other that will enable all to come through this time of adversity, adapt to the new normality of life, work, and the better times to come.

\section{Conclusion}

The authors would like to thank the numerous paramedics who have asked them for information about various aspects of COVID-19 which lead to the different sections and the rapid production of this article. We hope this article is useful in answering these queries and in supporting paramedics in their practice during these challenging times.

Finally, we also offer a disclaimer that while the the information and advice provided within this article is the most up-to-date currently ( $7^{\text {th }}$ April 2020). This is a rapidly changing field with the evidence base being added to daily (as evidenced by the multiple rewrites of this article within the past week!), therefore it is important that Paramedics keep up to date with the latest clinical guidance from their employers. 


\section{References}

1. HM Government, COVID19: Background Information, Public Health England. 2020: London. [cited $7^{\text {th }}$ April 2020]; Available from: https://www.gov.uk/government/publications/wuhannovel-coronavirus-background-information

2. Chen, T., et al., Clinical characteristics of 113 deceased patients with coronavirus disease 2019: retrospective study. BMJ, 2020. 368: p. m1091. Available from: https://doi.org/10.1136/bmj.m1091

3. World Health Organisation, Naming the coronavirus disease (COVID-19) and the virus that causes it. [cited $2^{\text {nd }}$ April 2020]; Available from:

https://www.who.int/emergencies/diseases/novel-coronavirus-2019/technicalguidance/naming-the-coronavirus-disease-(covid-2019)-and-the-virus-that-causes-it.

4. Razai, M.S., et al., Coronavirus disease 2019 (covid-19): a guide for UK GPs. BMJ, 2020. 368: p. m800. Avaliable from: https://doi.org/10.1136/bmj.m800

5. Chan, J.F.-W., et al., A familial cluster of pneumonia associated with the 2019 novel coronavirus indicating person-to-person transmission: a study of a family cluster. The Lancet, 2020. 395(10223): p. 514-523. Available from: https://doi.org/ 10.1016/s0140$6736(20) 30154-9$

6. $\mathrm{Xu}, \mathrm{X}$., et al., Evolution of the novel coronavirus from the ongoing Wuhan outbreak and modeling of its spike protein for risk of human transmission. Sci China Life Sci, 2020. 63(3): p. 457-460. Available from: https://doi.org/10.1007/s11427-020-1637-5

7. Huang, C., et al., Clinical features of patients infected with 2019 novel coronavirus in Wuhan, China. The Lancet, 2020. 395(10223): p. 497-506. Available from: https://doi.org/10.1016/S0140-6736(20)30183-5

8. Chen, N., et al., Epidemiological and clinical characteristics of 99 cases of 2019 novel coronavirus pneumonia in Wuhan, China: a descriptive study. The Lancet, 2020. 395(10223): p. 507-513. Available from: https://doi.org/10.1016/s0140-6736(20)30211-7

9. World Health Organisation, Coronavirus disease 2019 (COVID-19) Situation Report - 78. 2020: Geneva. [cited $7^{\text {th }}$ April 2020]; Available from: https://www.who.int/docs/defaultsource/coronaviruse/situation-reports/20200407-sitrep-78-covid-19.pdf?sfvrsn=bc43e1b_2

10. HM Government, Number of coronavirus (COVID-19) cases and risk in the UK, Department of Health and Social Care and Public Health England. 2020: London. [cited $7^{\text {th }}$ April 2020]; Available from: https://www.gov.uk/guidance/coronavirus-covid-19-information-for-thepublic

11. Guan, W.J., et al., Clinical Characteristics of Coronavirus Disease 2019 in China. N Engl J Med, 2020. Available from: https://doi.org/10.1056/NEJMoa2002032.

12. Remuzzi, A. and G. Remuzzi, COVID-19 and Italy: what next? The Lancet, 2020. Available from: https://doi.org/10.1016/s0140-6736(20)30627-9

13. Li, Q., et al., Early Transmission Dynamics in Wuhan, China, of Novel Coronavirus-Infected Pneumonia. N Engl J Med, 2020. 382(13): p. 1199-1207. Available from: https://doi.org/10.1056/NEJMoa2001316

14. Kucharski, A.J., et al., Early dynamics of transmission and control of COVID-19: a mathematical modelling study. The Lancet Infectious Diseases, 2020. Available from: https://doi.org/10.1016/s1473-3099(20)30144-4

15. Rothman, K.J., S. Greenland, and T.L. Lash, Modern epidemiology. 2008, Philadelphia, PA: Lippincott-Raven.

16. Lauer, S.A., et al., The Incubation Period of Coronavirus Disease 2019 (COVID-19) From Publicly Reported Confirmed Cases: Estimation and Application. Ann Intern Med, 2020. Available from: https://doi.org/10.7326/M20-0504

17. Bai, Y., et al., Presumed Asymptomatic Carrier Transmission of COVID-19. JAMA, 2020. Available from: https://doi.org/10.1001/jama.2020.2565 
18. HM Government, COVID-19: infection prevention and control (IPC), Public Health England. 2020: London [cited $7^{\text {th }}$ April 2020]; Available from:

https://www.gov.uk/government/publications/wuhan-novel-coronavirus-infectionprevention-and-control

19. Wang, W., et al., Detection of SARS-CoV-2 in Different Types of Clinical Specimens. JAMA, 2020. Available from: https://doi.org/10.1001/jama.2020.3786.

20. HM Government, Aerosol Generating Procedures (AGPS), Health Protection Scotland 2019: Glasgow [cited $7^{\text {th }}$ April 2020]; Available from:

https://hpspubsrepo.blob.core.windows.net/hps-website/nss/2893/documents/1_tbp-Iragp-v1.pdf

21. Gamage, B., et al., Protecting health care workers from SARS and other respiratory pathogens: a review of the infection control literature. Am J Infect Control, 2005. 33(2): p. 114-21. Available from: https://doi.org/10.1016/j.ajic.2004.12.002.

22. van Doremalen, N., et al., Aerosol and Surface Stability of SARS-CoV-2 as Compared with SARS-CoV-1. New England Journal of Medicine, 2020. Available from: https://doi.org/10.1056/NEJMc2004973

23. Tran, K., et al., Aerosol generating procedures and risk of transmission of acute respiratory infections to healthcare workers: a systematic review. PLoS One, 2012. 7(4): p. e35797.

Available from: https://doi.org/10.1371/journal.pone.0035797

24. HM Government, COVID-19: guidance for Ambulance Trusts, Public Health England. 2020: London [cited $8^{\text {th }}$ April 2020]; Available from:

https://www.gov.uk/government/publications/covid-19-guidance-for-ambulance-trusts

25. Li, J., et al., Defining Aerosol Generating Procedures and Pathogen Transmission Risks in Healthcare Settings. Open Forum Infectious Diseases, 2017. 4(Suppl 1): p. S34-S35. Available from: https://doi.org/10.1093/ofid/ofx162.085

26. Wax, R.S. and M.D. Christian, Practical recommendations for critical care and anesthesiology teams caring for novel coronavirus (2019-nCoV) patients. Can J Anaesth, 2020. Available from: https://doi.org/10.1007/s12630-020-01591-x

27. HM Government, COVID-19: investigation and initial clinical management of possible cases, Public Health England. 2020: London. [cited $7^{\text {th }}$ April 2020]; Available from: https://www.gov.uk/government/publications/wuhan-novel-coronavirus-initialinvestigation-of-possible-cases

28. HM Government, COVID-19: guidance for households with possible coronavirus infection, Public Health England. 2020: London. [cited $7^{\text {th }}$ April 2020]; Available from: https://www.gov.uk/government/publications/covid-19-stay-at-home-guidance

29. Brady, M., J. Jackson, and K. Northstone, Remote clinical decision making: Evaluation of a new education module. Nurse Educ Pract, 2018. 29: p. 150-158. Available from: https://doi.org/10.1016/j.nepr.2018.01.002

30. NHS England, More Than One Million People Use NHS 111 Online To Get Quick Advice About Coronavirus. 2020. [cited $7^{\text {th }}$ April 2020]; Available from:

https://www.england.nhs.uk/2020/03/more-than-one-million-people-use-nhs-111-onlineto-get-quick-advice-about-coronaviru

31. NHS England and NHS Improvement, NEXT STEPS ON NHS RESPONSE TO COVID-19. 2020. [cited $7^{\text {th }}$ April 2020]; Available from: https://www.england.nhs.uk/coronavirus/wpcontent/uploads/sites/52/2020/03/20200317-NHS-COVID-letter-FINAL.pdf

32. Lake, R., et al., The quality, safety and governance of telephone triage and advice services an overview of evidence from systematic reviews. BMC Health Serv Res, 2017. 17(1): p. 614. Available from: https://doi.org/10.1186/s12913-017-2564-x

33. Wheeler, S. and L. Mahlmeister, Risk Management in Telephone Triage Part 1: New Trends, Advances \& Risks. 2016. Available from: https://doi.org/10.13140/RG.2.2.32472.70407 
34. Royal College of General Practitioners, Top 10 Tips For COVID-19 Telephone Consultations. 2020; [cited $7^{\text {th }}$ April 2020]; Available from: https://www.rcgp.org.uk/about-us/rcgpblog/top-10-tips-for-covid-19-telephone-consultations.aspx.

35. Greenhalgh, T., G.C.H. Koh, and J. Car, Covid-19: a remote assessment in primary care. BMJ, 2020. 368: p. m1182. Available from: https://doi.org/10.1136/bmj.m1182

36. McCreary, E.K., and J.M. Pogue on behalf of the Society of Infectious Diseases Pharmacists, COVID-19 Treatment: A Review of Early and Emerging Options. Open Forum Infectious Diseases, 2020. Available from: https://doi.org/10.1093/ofid/ofaa105

37. Fang, L., G. Karakiulakis, and M. Roth, Are patients with hypertension and diabetes mellitus at increased risk for COVID-19 infection? The Lancet Respiratory Medicine, 2020. 8(4). Available from: https://doi.org/10.1016/s2213-2600(20)30116-8

38. Tignanelli, C.J., et al., Antihypertensive drugs and risk of COVID-19? The Lancet Respiratory Medicine, 2020. Available from: https://doi.org/10.1016/s2213-2600(20)30153-3

39. The Renal Association, The Renal Association, UK position statement on COVID-19 and ACE Inhibitor/Angiotensin Receptor Blocker use. 2020. [cited $7^{\text {th }}$ April 2020]; Available from: https://renal.org/covid-19/ra-resources-renal-professionals/renal-association-uk-positionstatement-covid-19-ace-inhibitorangiotensin-receptor-blocker-use/

40. British Cardiovascular Society, BSH \& BCS Joint statement on ACEi or ARB in relation to COVID-19. 2020 [cited $7^{\text {th }}$ April 2020]; Available from:

https://www.britishcardiovascularsociety.org/news/ACEi-or-ARB-and-COVID-19.

41. Aronson, J.K. and R.E. Ferner, Drugs and the renin-angiotensin system in covid-19. BMJ, 2020. 369: p. m1313. Available from: https://doi.org/10.1136/bmj.m1313

42. Qiao, W., et al., Ibuprofen attenuates cardiac fibrosis in streptozotocin-induced diabetic rats. Cardiology, 2015. 131(2): p. 97-106. Available from: https://doi.org/10.1159/000375362

43. Russell, B., et al., COVID-19 and treatment with NSAIDs and corticosteroids: should we be limiting their use in the clinical setting? Ecancermedicalscience, 2020. 14: p. 1023.Available from: https://doi.org/10.3332/ecancer.2020.1023

44. HM Government, Ibuprofen use and Coronavirus (COVID-19), Medicines and Healthcare product Regulatory Agency. 2020: London. [cited $7^{\text {th }}$ April 2020]; Available from: https://www.gov.uk/government/news/ibuprofen-use-and-covid19coronavirus

45. Royal Pharmaceutical Society, Advice on NSAIDs and COVID-19, in The Pharmceutical Journal. 2020. Available from: https://www.pharmaceutical-journal.com/news-andanalysis/news-in-brief/advice-on-nsaids-and-covid-19/20207839.article?firstPass=false

46. NHS. Think Kidneys. 2020 [cited $7^{\text {th }}$ April 2020]; Available from:

https://www.thinkkidneys.nhs.uk/.

47. Resuscitation Council (UK), Statements on COVID-19 (Coronavirus). 2020: London. [cited $7^{\text {th }}$ April 2020]; Available from: https://www.resus.org.uk/media/statements/resuscitationcouncil-uk-statements-on-covid-19-coronavirus-cpr-and-resuscitation/covid-healthcare/

48. Resuscitation Council (UK), COVID-19: FAQs for Healthcare Professionals. 2020: London. [cited $7^{\text {th }}$ April 2020]; Available from:

https://www.resus.org.uk/media/statements/resuscitation-council-uk-statements-on-covid-

19-coronavirus-cpr-and-resuscitation/faqs-on-cpr-during-the-covid-19-pandemic/

49. Greenberg, N., et al., Managing mental health challenges faced by healthcare workers during covid-19 pandemic. BMJ, 2020. 368: p. m1211. Available from:

https://doi.org/10.1136/bmj.m1211

50. Murray, E., Moral injury and paramedic practice. Journal of Paramedic Practice, 2019. 11(10): p. 424-425. Available from: https://doi.org/10.12968/jpar.2019.11.10.424

51. Williamson, V., N. Greenberg, and D. Murphy, Moral injury in UK armed forces veterans: a qualitative study. European journal of psychotraumatology, 2019. 10(1): p. 1562842-

1562842. Available from: https://doi.org/10.1080/20008198.2018.1562842 
52. Williamson, V., S.A.M. Stevelink, and N. Greenberg, Occupational moral injury and mental health: systematic review and meta-analysis. The British Journal of Psychiatry, 2018. 212(6): p. 339-346. Available from: https://doi.org/10.1192/bjp.2018.55

53. World Health Organisation, Rolling Updates on Coronavirus Disease (COVID-19) Updated 23rd March 2020. [cited 25 $5^{\text {th }}$ March 2020]; Available from:

https://www.who.int/emergencies/diseases/novel-coronavirus-2019/events-as-theyhappen

54. Tedeschi, R.G. and L.G. Calhoun, TARGET ARTICLE: "Posttraumatic Growth: Conceptual Foundations and Empirical Evidence". Psychological Inquiry, 2004. 15(1): p. 1-18. Available from: https://doi.org/10.1207/s15327965pli1501_01

55. Joseph, S. and P.A. Linley, Trauma, recovery, and growth: Positive psychological perspectives on posttraumatic stress. Trauma, recovery, and growth: Positive psychological perspectives on posttraumatic stress., ed. S. Joseph and P.A. Linley. 2008, Hoboken, NJ, US: John Wiley \& Sons Inc. xi, 372-xi, 372.

56. Mental Health Foundation, Looking After Your Mental Health During the Coronavirus Outbreak. 2020 [cited $7^{\text {th }}$ April 2020]; Available from: https://www.mentalhealth.org.uk/publications/looking-after-your-mental-health-duringcoronavirus-outbreak 